\title{
El tiempo y la vida anímica normal.
}

\section{Dificultad de la psicología del tiempo}

Nada hay más efectivo y concreto para el hombre que el tiempo que vive en câda instante de su existencia. El momento, este momento, a pesar de st fugacidad y aunque lo empleemos o suframos-lamentablemente, en general es la realidad viva, la realidad plena, la realidad por excelencia, luz frente a la cual todo lo denás es sólo sombra y tinieblas. En él revela cada cual tanto la peculiaridad de su disposición cuanto la índole de las circunstancias que le rodean; y la manera como ocurre Jer el almacestal iacutalidadosingular constituye la fuente más original del conocimiento psicológico. Sin embargo, es tarea imposible aprehender directamente la realidad del tiempo presente. Si quiero analizar cómo vivo el instante, encuentro que éste no se da a mi sentido íntimo de la misma manera que los objetos que percibo o los datos sobre los que reflexiono. Si en mi examen logro una vislumbre del momento fugitivo, éste ya no es tiempo presente, sino pasado, realidad que fué, pálida y estática sombra. En lugar de sorprender la vida palpitante del devenir original, alcanzo sólo a ejecutar algo así como la disección del cadáver que sería el tiempo pensado. Con la aprehensión del tiem- 
po que vivinos ocurre, pues, lo propio que con el tiempo mismo, según lo expresó insuperablemente SAN Agustín: "Quid est ergo tempus? Si nemo ex me quaerat, scio; si quaerenti explicare velim, nescio". *

Los procedimientos menos apropiados para penetrar el fenómeno del devenir son los que aplica la psicología experimental, pues sus artificios tienden a verificar los datos objetivos y los rendimientos del complejo psicofisiológico, esto es, los residuos y las condiciones, no lo actual y genuino de la conciencia. Esto no impide que el método experimental sea útil para determinar la cuantía y los límites temporales de ciertos hechos o circunstancias. Así se ha podido determinar en el hombre la đuración mínima normal de un instante vivido. Fuera de las escasas adquisiciones positivas logradas en este camino, el criterio cuantitativo del tiempo entraña un peligro para el estudio y la idea de la actividad anímica. En efecto, de una concepción de la vida, íntimamente relacionada con las pretensiones de la psicología experimental y fomentadora de las desmesuras desla psicotecnia, ha nacido el concepto del tiempol métrico ycsu aplicación a las cosás humanas. Pues la creencia en la igualdad de los instantes y su susceptibilidad de cálculo, según observa KLAGES, "destemporaliza el tiempo y es medida de lo que nunca puede medirse", cuyo extremo remata en el artículo de fe de los adoradores de Mammón: time is money.

A esta concepción que desnaturaliza el sentido del tiempo se opone un criterio cualitativo, que ve en el devenir ante todo cambio, transformación y novedad en el curso contínuo e irreversible de su dirección. Adicto a la espontanei* "Pues ¿qué es el tiempo? Si nadie me lo pregunta, lo sé; pero si
intento explicarlo, ya no lo sé"? 
dad de la vida, este criterio tiene remotos antecedentes en la ingenua significación de las palabras. El genio del lenguaje revela, efectivamente, que el sentido más primitivo del término "tiempo", y que todos entendemos todavía, se relaciona con la situación cambiante del hombre en la naturaleza. * Así, la noción de tiempo relativa a las impresiones que vivimos, del tiempo que hace, esto es, "el carácter meteorológico del momento actualmente vivido" (РісHON), es anterior a la noción de tiempo que transcurre.

La adhesión al concepto de la índole cualitativa del tiempo vivido, entraña igualmente una dificultad para nuestra tarea, que es preciso señalar aquí. Así como no es aceptable en psicología la concepción del tiempo como si fuese homogéneo y susceptible de medida, aunque sea legítima en la vida práctica y en diversas ciencias, así también resulta inapropiado incorporar sin discernimiento a nuestra disciplina teorías metafísicas del tiempo, por más que se aproximen a la entiđad del transcurrir anímico. Esta proximidad es precisamente la fuente de dificultades para una apropiación renovadora y plausible, por parte de la psicología, de los datos que nos ofrece la reflexión de los filósofos en este dominio del saber, tan poco favorable a la aprehensión justa de los fenómenos. Nos parece lícito que, evitando tomar partido por un sistema determinado, no rehusemos la información y las vislumbres que nos brinda esta clase de investigaciones, iniciada ya por Heráclito. Por lo demás, bien puede correrse el riesgo de dar eventualmente un giro más filosófico que psicológico al estudio de la conciencia del tiempo, ya

* Esto es efectivo no sólo para temprs, sino para sus equivalentes en iảiomas de origen diferente al latín. Así, en quechua, "pacha" equivale no sólo a "tiempo", sino a "mundo" y "espacio". 
que ha avanzado casi exclusivamente por obra de los filósofos. Si nos contentásemos con lo que dicen los psicólogos, no tendríamos sino unas pocas trivialidades, más relacionadas con la forma y las condiciones temporales de algunos aspectos de la vida anímica que con la conciencia misma del tiempo.

Nos referiremos, por último, a las dificultades existentes acerca de la manera como se relacionan la actividad psíquica y el tiempo. Siendo impenetrable la naturaleza de éste, no podemos considerarlo como objetivo ni como subjetivo, ni tampoco como anterior a la separación de lo interno y lo externo. Asimismo, no cabe afirmar o negar que la actividad psíquica sea el devenir, o que el alma meramente verifica o refleja el orđen de la sucesión de las cosas, sea de manera directa, sea in modo obliquo. En fin, no alcanzamos a determinar si el fluir del tiempo corre en nosotros del pasado al porvenir o, por el contrario, del futuro al pretérito. En todo caso, nos parece justificado suponer una intencionalidad sui generis - tan esencial e inherente a la vida anímica del hombre como la intencionalidad transitiva, dirigida a los objetos, y la intencionalidad reflexiva, vuelta al yo-, una intencionalidad (o si se quiere, una dirección de la intencionalidad) abierta al devenir, gracias a la cual la experiencia vivida no es una suma de sucesos más o menos aislados, más o menos asociađos, sino una continuidad estructurada, una formación histórica personal en que son eficaces inclusive los hechos olvidados y los anhelos imprecisos.

\section{Aspecto temporal de las funciones psíquicas}

El hecho de vivir el tiempo nunca se nos ofrece como una experiencia pura, desvinculada de todo otro fenómeno 
mental, sino como aspecto o factor constitutivo de $\cdot$ la realidad empírica que llena el alma. Ciertamente, en algunos momentos, la significación temporal puede destacarse de manera preponderante, pero siempre con algo más en el fonđo que la conciencia del tiempo. KLAGES imagina que el tiempo es el alma del espacio. Igualmente puede decirse en sentido figurado que el devenir se comporta con el caudal de los fenómenos anímicos, como el alma se conduce con el cuerpo vivo. Las diversas maneras de manifestarse la actividad de nuestra mente se relacionan con la conciencia del tiempo en forma que varía según la calidad de cada una de aquéllas. La percepción, la meomoria, el sentimiento, el pensamiento, la voluntad, lo mismo que el conjunto de la vida anímica, son fenómenos temporales; pero además se muestran como condición o contenido de modalidades especiales de la conciencia del tiempo.

I. En la relación de nutestro ser con el mundo, la percepción condiciona y concreta la conciencia del tiempo, sin que esto signifiquel tua averdadera percepción sensorial del tiempo. El hecho aparece ciarảmente envarimpresión cuantitativa del tiempo vivido. En efecto, se sabe desde las clásicas investigaciones de Mrumann, que comparando dos lapsos de igual duración, de los cuales uno es lleno de sensaciones y otro ocupado con pocas sensaciones, parece mayor el primero, si se trata de tiempos breves o muy breves; pero si se trata de lapsos grandes, sucede lo contrario: el tiempo rico en sensaciones parece más pequeño que el otro. $\mathrm{Na}$ turalmente, eso ocurre siempre que en el estado del sujeto no dominen sentimientos o tendencias capaces de modificar la estructura temporal. Por otra parte, toda percepción se realiza conforme a una perspectiva temporal dentro de la 
que se sitúa cađa objeto. Así, el ritmo es la estructura anímica en que el contenido de la percepción se organiza de la manera más típica con el tiempo. Ahí lo percibido es como la materia que se somete a la forma de la intencionaliclad temporal.

La determinación exacta de los intervalos de duración mínima asequible a la conciencia sólo puede lograrse gracias a comprobaciones microcronométricas del efecto de estímulos sticesivos. De este modo puede apreciarse el tiempo más estrecho dentro del cual cabe la distinción de un "antes" y un "después", que varía según los órganos de los sentidos. Normalmente es de I/ro a I/20 de segundo para la vista, de I/40 para el tacto, de I/IOO para el oído. Estas fracciones de segundo no son, sin/embargo, las menores que pueden comprobarse experimentalmente en materia de diferencias posibles entre excitaciones sensoriales eficaces. Se ha verificado la de I/700o entre dos excitaciones sucesivas, en dos sitios diferentes del cuerpo, para el sentido de la vibración; de I/ 10000 para el tacto, y hastas de 22 millonésimos de segundo para el ó́do. Es interesanteosaber que incluso la calidad del estímulo puede discernirse con una excitación que dura brevísimo tiempo; así basta el contacto de $\mathrm{I} / 300$ de segundo para percibir por sólo la vibración si un objeto golpeado es metal, mađera o cartón. No hemos mencionado hasta ahora la quinestesia. Sin embargo, interviene muy activamente en la experiencia del tiempo, por lo menos como acompañamiento de fondo, pues no sólo participa en la percepción de ciertos ritmos corporales, como la respiración, sino que tiene relación con todo movimiento de nuestro organismo, y no hay percepción, ni siquiera señsibilidad 'alguna, sin movimiento real o virtual. 
La capacidad de distinguir impresiones sensoriales más o menos próximas en el tiempo, y por consiguiente la duración del momento mínimo de la experiencia, đepende de la manera como están constituídos el sistema nervioso y los órganos de los sentidos. Así se explica que mientras el hombre puede ver I8 movimientos sucesivos en un segundo (o sea que su momento visual mínimo es de I/I8 de segundo), el caracol no percibe sino 3 y el pez luchador logra la visión hasta de 50 . Por consiguiente, una varilla que oscila 6 veces por segundo parece al hombre animada de un movimiento rápido, a los ojos del pez cambia lentamente de posición y para la sensibilidad del caracol resulta un cuerpo inmóvil. Hechos de esta clase, que hoy pueden analizarse con la "cámara lenta" del cinematógrafo, permiten comprender aquellas apariencias del mundo peculiares a cada especie de animales, acerca de cuya entidad insiste tanto voN UEXKüLL. Ya a mediados del siglo pasado el famoso biólogo K. E. voN BAER, investigó el momento mínimo de la experiencia humana, y especulởa ácerca de das correspondientes diferencias. Supuso que la duración dẹ la lvida de los animales depende de la amplitud de su momento elemental, y que todas las especies viven idéntico número total de momentos. Aunque hoy no puede aceptarse un elemento temporal único, por el hecho de que la duración del momento mínimo depende del órgano sensorial que se considere - según antes hemos visto en el caso del hombre-, la especulación de voN BAER conserva su significación para dar idea, grosso modo, de los diferentes aspectos en que se presenta la realidad exterior a los seres diversamente constituídos en lo que respecta al tempo de su impresionabilidad sensorial. Según esa ficción, a las criaturas cuya vida dura un día, y que en un segundo 
pueden recibir miles de sensaciones sucesivas, la bala disparada con una pistola les parecería casi inmóvil por la lentitud de su progreso. En cambio, para los seres que viviesen tantos milenios como el hombre vive años, nuestros movimientos les resultarían invisibles por su velociđad; percibirían claramente el crecimiento de las plantas, y el Sol se les ofrecería animado de un movimiento tan rápido que lo verían como una línea de fuego interrumpida por breves intermitencias, correspondientes a la obscuridad de las noches.

2. ${ }^{\circ}$ Con respecto a la memoria, la conciencia del tiempo tiene en ella una condición esencial, pues sin su concurso apenas podríamos recibir del tiempo más que la impresión ae su pasar. Viviríamos el momento presente y el tiempo futuro de manera muy simple, sin fondo de continuidad, sin organización histórica. Pero no es menos evidente que la conciencia del tiempo es necesaria para la integridad y precisión de las operaciones de la memoria, ya que permite localizar el recuerdo, situario en un "cuando" determinado. Sin esto la memoria ne seríal abšlutamente cronológica. *

$3 .^{\circ}$ La relación de la conciencia deb tiempo con la vida afectiva es más compleja. Esquemáticamente podemos señalar dos modalidades de tal relación: aquella en que la dirección temporal es factor predominante en la estructura de ciertos sentimientos y aquella en la cual la modificación de la conciencia del tiempo se produce por ingerencia de teterminada condición afectiva. Los sentimientos con dirección temporal predominante se caracterizan porque en su manifestación el yo vive de manera inmediata y unitaria tanto

\footnotetext{
* Bergson y Husser han analizado con profundidad las relaciones existentes entre la memoria y el tiempo, pero desde un ptinto de vista más filusó-
fico que psicológico.
} 
el estado afectivo cuanto la intencionaliclad temporal. Se constituyen y configuran y dan carácter especial al conjunto de la actividad anímica por orientarse al presente, al futuro o al pasado. En efecto, hay estados de ánimo y estados afectivos sensoriales que no sólo dependen de la condición psicofísica presente, sino que tienen sentido únicamente por referirse al instante actual, como ocurre con el malestar físico premonitorio de las enfermedades infecciosas, en que incluso todo recuerdo y todo incentivo del porvenir resultan indiferentes y vacíos; hay igualmente estados afectivos con objeto que no sólo son actuales por depender de la situación del momento, sino porque se proyectan en la esencia temporal del "ahora", según acontece con determinadas formas del aburrimiento, la sorpresa o el júbilo, que, respectivamente, vivimos con clara conciencia de que la temporalidad pesa sobre nosotros, que nos ofrece una revelación o que nos llena con su plenitud fugaz. Lo que se observa con el tiempo presente se manifiesta con el futuro y el pasado. Basta mencionar la esperanza y eltemer, los dōs sentimientos más claramente prospectivos, y la nostalgia y el arrepentimiento, retrospectivos por excelencia, para comprender la fuerza pocierosa que tienen en el alma lo por venir, problemático como es, y lo pretérito, inexistente ya en el mundo sensible.

La segunda modalidad de la relación entre la conciencia del tiempo y la vida afectiva no es primaria, como la anterior, sino de simple modificación del contenido específics, de suerte que el sentimiento contribuye a dar carácter al devenir en el aspecto cuantitativo de la duración. Así, quien vive un momento agradablemente, lo encuentra breve; a quien es presa del desagrado y más aún de la impaciencia o de la angustia, le parece que el tiempo no corre. 
$4 .^{\circ}$ El ejercicio del pensamiento discursivo influye te manera adversa sobre la experiencia ingenua de la realidad temporal. Por obra de la disciplina racional, el momento presente palidece y se destrbstancia; es sacrificado como mero recipiente de elaboraciones de lo pasado y como medio para planear lo futuro, si no sirve de agente en el empeño de desasir toda temporalidad. Es innegable que el afán de abstracción y ley, inherente a la actividad intelectual, familiariza al alma con lo idéntico, lo invariable, lo intemporal, y la desliga del inmediato y concreto fluir de la vida. El auge de la ciencia y de la técnica ha contribuído de manera poderosa a que el hombre moderno rompa sistemáticamente la conexión con su mundo efectivo, con stu presente pleno y cargado de significaciones, con sut tradición formadora y con sus encantadoras aspiraciones, abstrayéndolo de la tierra sin remontarlo al cielo. De ahí la reacción irracionalista, que cobra vigor con las advertencias de Nietzsche, quien, anticipándose a BERGSON, proclama que "nuestro intelecto no está constituído para comprender eldevenir, sino para probar la rigidez general"'.

Contrariamente al pensamiento discursiro, el intuitivo y sobre todo la imaginación, tanto pueden empobrecer el tiempo vivido como enriquecerlo. Y no sólo merced a la creación de un futuro ilusorio, sino insinuando a la vida anímica el acceso del mundo de las impalpables realidades del presente entrañable, del pasado significativo y del futuro cuyas posibilidades palpitan ya en nuestro destino. La virtud positiva de la fantasía - sea lúdica, mítica, poética, metafísica o de cualquier género- es poner al alma en relación con verdades superiores de la existencia.

$5 .{ }^{\circ} \mathrm{El}$ acto voluntario tiene aspectos que pueden ser simul- 
táneos o sucesivos: motivación, deliberación etc.; y la dinámica del conjunto del querer se diferencia y perfecciona con el concurso del tiempo, que enriquece y renueva el caudal de incentivos, y permite la adquisición y afianzamiento de formas de conducta eficaz. Pero también el ejercicio de la voluntad repercute sobre la conciencia del tiempo de dos maneras semejantes a las del pensamiento. En general, la conducta prefijada contribuye a que pierda su entidad virgina! el tiempo que se interpone entre el deseo o el proyecto y la meta alcanzada, mayormente si la atención se dirige a los instantes que se suceden en la espera. La forma de existencia en que la acción es aprisa, monótona, con todas las circunstancias previstas, como acontece con el trabajo "racionalizado", orgullo de la técnica moderna, deja en el alma la impresión de no vivir los instantes, sino de dividirlos y oct1parlos mecánicamente, percliéndose la vida en una actividad vacía. Por el contrario, el querer que se convierte en acción creadora gracias a la libertad, el querer que expresa en decisiones y en obraşlas ỹirtualidades más intinas y genuinas de la personalidad, significa tiempo pleno deyenir fructífero, existencia cumplida.

\section{Organización temporal del conjunto de la vida anímica}

Complementario de la propiedad fundamental de permanencia activa - en cuya virtud se conserva la propia identidad - es el cambio incesante de la vida anímica personal, su configuración en el tiempo. Permanencia y mudanza hacen la continuidad del sujeto anímico y de la estructura de su existencia, cuyos "presentes" sucesivos de otro modo carecerían de sentido y de trascendencia. La articulación de los momentos personales no es determinada por la inercia 


\section{二 $\mathrm{r}_{32}$ 二}

del pasado ni por la previsión del futuro, sino por la intencionalidad misma, que conecta a la temporalidad el ser del hombre, con sus disposiciones, su experiencia acumulada y sus incentivos. Este modo de ver esquemático y de merat aproximación no significa que entendamos la temporalidad y la vida anímica como entidades que se combinan, pues, según la expresión de Minkowski, "el devenir, cargado de corrientes subterráneas y pođerosas, concentra en sí el sentido mismo de la vida, así como el senticlo del yo; y el yo, en su impulso personal, como que se entrecruza con estas corrientes". Por otra parte, el cumpliniento concreto de la contintidad de la vida anímica personal depende también de condiciones extrínsecas, de la misma manera que la ruta del caminante depende tanto de su naturaleza e intenciones como de las particularidades y accidentes del terreno.

Aquí consideramos la organización del conjunto de la vida anímica atendiendo principalmente al devenir personal, al proceso del mundo interior, cuya comprensión, naturalmente, requere que tse Cacivierta êl confacto con el mundo exterior. Posteriormente, al tratavel terna de la historicidad, examinaremos el proceso de la existencia en relación con el devenir extrapersonal y con el sentido de la eternidad.

En su escrito memorable intitulado "Ideas acerca de itha psicologia descriptiva y analítica" (1894), Dilthey ha enumerado las condiciones que configuran la evolución de la vida anímica individual. Además de la influencia del desarrollo corporal, del medio físico y del mundo espiritual, sin precisar detalles, señala las condiciones siguientes: la continuidad subjetiva inmanente, los valores de la existencia, las condiciones vitales, los acoplamientos anímicos adquiridos y los actos creadores. Este ésquema servirá đe guía a 
nuestra exposición del asunto indicado, diferente del propósito perseguido por Dilther, aunque no ajena del todo.

I. La continuidad inmanente tiene a las tendencias instintivas y a los sentimientos como fuerzas principales o agentes propulsores. En cada instante de nuestra vida se manifiestan movimientos internos correspondientes a las más variadas tendencias del instinto. Lo que se actualiza en nuestra alma no es un simple fluir de esta o aquella propensión, sino un verdadero concierto - con disonancias y contraposiciones- de tendencias que nacen, se despliegan y esfuman en una estructura de fondc, compleja y singular. La marcha del tiempo se confunde con la generación y metamorfosis de estas potencias irracionales, ctya espontaneidad constituye el caudal dinámico de la actividad psíquica. Sin embarco, sería extremar demasiado la importancia del instinto si lo considerásemos cono el elemento primario y derisivo de la configuración temporal de la vida anímica. E1 devenir subjetivo no se ređuce al contenido de nuestras tendencias y estados afectivos; éste lo llena y colora, da fisonomía a su ajuste, pero"ni las tendencias instintivas" ni los sentimientos constituyen el ajuste mismo, la forma de la duracion viva $y$ operante. En este sentido es irrefutable la sentencia de Siraus: "Tanto como las sensaciones, las tendencias instintivas sólo son material de la experiencia viva”. Los psicoanalistas se empeñan en sostener lo contrario: en eso consiste la flaqueza de su concepción general, que, como el mecanicismo, considera el todo. la estructura y el desarrollo consecuencias de la causalidad elemental. Esto no impide reconocer que las fallas de la teoría psicoanalítica no disminuyen el mérito del movimiento de ideas que ha originado en lo que respecta a la inteligencia de las transformaciones de la vida 
mental dando valor al instinto, al dinamismo de las estructuras y al examen genético đe los episodios de la carrera personal.

Esta referencia es pertinente aquí, donde también debemos mencionar uno de los procesos más genuinos de la organización temporal de la vida anímica en que intervienen las tendencias instintivas. Nos referimos a la sublimación, uno de los hallazgos psicológicos de Nietzsche, de que se apropió Freud y del cual da una imagen magistral Dilthey en su mencionado escrito de 1894 . He aquí sus palabras: "Cada época de la vida tiene en sí un valor propio, pues por su peculiar condición a cada una corresponde animar una realización, un cumplimiente, capaz de sentimientos que elevan y amplían la existencia... Los estados que constituyen la serie del desarrollo, con da eficacia de la continuidad estructural adecuada, forman un proceso creciente de adaptación gracias a la diferenciación, la ampliación y las sintesis superiores. Y es muy importante que con este vasto proceso las tendencias instintivas elementales mengüien en energía por su satisfacción normal y predan dejar lugar a las tendencias superiores? Justamente, en virtud de esa continuidad de una serie ascendente, estos estados constituyen un desarrollo. Están, pues, tan íntima y ąpropiadamente ligados, que en el curso del tiempo hacen posible un despliegue amplio y rico de los valores de la existencia. En eso consiste cabalmente la naturaleza del desarrollo en la vida humana. Cada época de la vida tiene su valor; pero en el progreso de la misma se desenvuelve una configuración de la vida anímica más articulada, formada en integraciones más altas".

La sublimación no puede, pues, ser considerada mero efecto de las influencias externas que, según la teoría Đsico- 
analitica, ofrecen objetos cada vez más espirituales a la adhesión del impulso sexual del individuo en crecimiento. La, sublimación es sólo un aspecto, sin duda relevante, de la naanera como participa el instinto en la formación concreta del devenir subjetivo, en el cual son patentes la periodicidad, las fases de incremento y declinación, sucesión y sustitución. El instinto se confunde por una parte con el trozo de naturaleza que es nuestro cuerpo, en el cual se reflejan los cambios temporales de lo externo: la alternación del día y la noche, las estaciones del año y demás períodos cósmicos; y de cuya formación y funcionamiento dependen aspectos importantes cie la evolución de la personalidad, así como propiedades del temperamento, entre las que sobresale el tempo psicofisiológico: flúido o pesado, rápido o lento, uniforme o cíclico. Por ctra parte, las manifestaciones del instinto tienen polaridades y gradaciones que en cierto modo van al encuentro de las formas más delicadas de la vida espiritual. Por eso no vacilamos en considerarà das téndenciaseinstintivas como conexión vivificante del alma con la naturaleza Nacla nos parece más falto de sentido que la difundida manera de reputar al instinto simple automatismo o concatenación mecánica de reflejos del sistema nervioso. Tal concepción, ciega para la entidad de lo orgánico y espontáneo, sólo puede nacer de una mentalidad utilitaria, incapaz de amor y simpatía por la naturaleza, sin cuyos sentimientos no es posible la comprensión de su realidad profunda. $\mathrm{Y}$ es precisamente semejante clase de comprensión la que nos permite aquilatar lo que hay en el instinto de fuerza germinal, de causa capaz para actuar sobre el destino, de potencia vegetativa sujeta a maduración y compás, que influye en la determinación de los 
ritmos, los ciclos y la trabazón evolutiva inherentes al clevenir cle la vida anímica.

2. Dilthey refiere lia continuidad estructural psíqutica también a la tendencia apropiada para desarrollar, conservar y elevar valores de la vida. A nuestro entender, aparte del hecho general de que la aprehensión y la realización de valores se despliegan en el tiempo vivido, las particularidades de la continuidad mencionada dependen de la estimativa principalmente por tres clases de condiciones de la valoración personal concreta, a saber: la clase de valores dominantes, la época del logro de los bienes más preciados, y la virtud del amor para configurar el ritmo de la existencia.

a) El ejercicio de la estimativa repercute sobre la estructura del devenir personal de manera que varía según la clase de los valores predominantes en la actividlad subjetiva. Aquí no podenos examinar todas la posibilidades correspondientes, por to cual nos contentaremos con señalar, a manera de ejemplo, lo que sucede en tres tipos extremos de dirección yalorativa. En primer término consideremos el del hombre en cuya tabla de yalores tienen la preferencia los hedónicos. E1 sujeto dado a los placeres, sin duda disfruta del presente con relativa vivacidad, pero sólo en un plano inferior, pues el objeto real de los valores hedónicos es el propio organismo, por sus sensaciones y estaclos afectivos sensoriales. Además, consumada la satisfacción momentánea, el tiempo significa poco, es cosa que perder en espera de nuevo disfrute. La estructura temporal de la vida anímica resultante de esta dirección de la estimativa se caracteriza por el abandono: la temporalidad está supeditada al compás cie los apetitos y al azar de las ocasiones de satisfacerlos. No inquietándose por el sentido de la vida sino por la vicla de 
los sentidos, el sibarita evade todo esfuerzo, mayormente si es penoso, y se esclaviza a su pasión, cuyo ritmo marcan el cleseo y el hartazgo. Su alma no se abre a la riqueza y variedad del devenir ni conoce la tensión fecunda: en naturalezas pasivas se entrega negligente al tránsito de las tentaciones, $y$ en las activas la sed de goces la agitan desordenadamente.

Veamos ahora lo que pasa con el tipo utilitario. Quien tiene abiertos los ojos del espíritu principalmente a los valores económicos, en medida proporcional vive el presente como međio, sacrificándolo aí empeño de incrementar los bienes materiales. El curso de su actividad es perpetua transición hacia el logro o el fracaso de la finalidad codiciada, que a menudo tiene el carácter de bien puramente cuantitativo. Esto no excluye cierta regularidad en la acción y algunos momentos colmados por el esfuerzo y el triunfo. Pero el trabajo ejecutado en vista de acumular bienes es, en general, vacío para la duración personal. En efecto, consecuencia de semejante carrera en pos de lo finito ês no sólo la desvaloración del ser auténtico de la persona, que acaba por convertirse también en instrumento o factor de la empresa, sino la prisa, forma especial de la temporalidad humana, que por someterse a las contingencias de las cosas trocables del mundo, priva de calidad substancial al devenir y a la existencia misma.

En cambio, en el tipo cuya tabla de valores se expande por lo alto, al que pertenecen el verdadero amador, el artista, el investigador, el héroe y el santo, el tiempo es eminentemente substancial. Pues quien se da de preferencia a los valores de las cosas por sí mismas, de las personas, de la naturaleza, del espíritu, vive la duración de manera profunda. 
En el fluir de su existencia alternan momentos de elevación, de plenitud y entusiasmo, en que el tiempo le ofrece todo lo que puede darle, incluso la trascendencia de lo temporal, con momentos triviales, vacuos, negativos. La estructura peculiar de su devenir no es ni el abandono ni la prisa, formas de la temporalidad vulgar, sino la tensión, forma creadora propia de la duración fructífera.

b) En cada época de nuestra viđa se cumplen nuestros deseos y aspiraciones en grado y manera que dependen de diversas causas. Tienen especial importancia para la organización temporal de la vida psíquica los referentes a los bienes más apreciados. Si de éstos se disfruta o se carece en la oportunidad debida, o si su logro se espera de un futuro indeterminado, la disposición del sujeto será diferente en lo que respecta a la valoración tanto del pasado cuanto del presente y el futuro. Cuando los bienes apetecibles en la niñez y la juventud han sido plenamente alcanzados y es difícil o imposible la adquisición de los propios de la edad adulta, el individuo tiende a sobrevalorar su pasado, y con él el pasado en general, yel presente y el futuro se le presentan hasta cierto punto como modalidades degradadas de la temporalidad. La actitud íntima así condicionada inclina la actividad anímica, sobre todo la afectiva, en el sentido de una continua o frecuente retrospección, particularmente aguda cuando el acaecer actual o la perspectiva del porvenir se presentan ingratos o llenos de dificultades y peligros. Se comprende que el anciano tenga a menuđo la misma propensión - laudator temporis acti- ya que la limitación del tiempo que le queda por vivir no le permite esperar mayores bie-
nes. 
Lo contrario se verifica en las personas cuyo pasado se caracteriza principalmente por la experiencia de los bienes frustrados, así como en aquellas que por otras cạusas - sobre todo de orden social- esperan del futuro los mayores logros. Para ambas clases de personas el pasado es en cierto modo negativo, el presente promesa, y el porvenir realidad por excelencia, verdadera plenitud de los tiempos. En este caso la expectación imprime su sello a la vida interior y la ilusión del progreso colora sus manifestaciones. Apenas necesitamos añadir que es normal y explicable la propensión del joven a asumir esta actitud de sobrevaloración del futuro.

c) El amor tiene la virtud de configurar el ritmo de la existencia, no sólo por el género de valores que aprehende, sino por el movimiento que imprime al conjunto de la actividad anímica. Es difícil oponerle otra fuerza capaz de producir transformaciones mayores en el mundo interior. Por eso es comprensible que tanto la conciencia del tiempo como la articulación de la lvida del alma no se sustraigan a su imperio. Si de alguna modalidad del tiempo concreto puede decirse que es lo contrario del que fluye irreparablemente - fugit irreparabile tempus (VIRGILIO) - es del que ilumina el amor. Pues la plenitud y la tensión del devenir amoroso no limitan su influencia a los momentos de su actualidad: ésta, débil o vigorosa, según las personalidades, trasciende a la vida ulterior modelando en algo el modo de sentir del hombre, incluso matizando su concepción general de la existencia. Este es el sentido psicológico profundo del dicho francés: on revient toujours à ses premiers amours. Un gran amor -acontecimiento sumamente raro en el común de los hombres- es capaz de comunicar su figura melódica, su es- 
tilo, a todos los aspectos relevantes del destino personal. "En todo amor auténtico se produce siempre el acontecimiento del Reino de Dios, acontecimiento de otro plano del ser, diferente del de nuestro mundo decaído" (Berdiaffr). Por el contrario, un amor al alcance de todos los corazones es a menuđo sólo un episodio sin mayores consecuencias. Suponemos se entenderá que aquí no nos referimos sólo al amor de los amantes, una de las especies del género a que pertenecen el amor a Dios, el amor entre padres e hijos, el amor a la tierra natal, a las ideas etc.

$3 .^{\circ}$ Dilthey se refiere a la adaptación de las impresiones a las "condiciones vitales", incorporada en la articulación de la vida anímica por las tendencias instintivas y los sentimientos que organizan la relación con el mundo exterior, por los intereses, la atención etc. Con propósito de mayor precisión consideraremos en este lugar no meramente las impresiones y las condiciones vitales en el sentido de DILTHEY, sino las situaciones, en su amplia significación organizadora de labvidaianímica personal Sibien éstas dependen de las disposicionespdinámicas codelemodo peculiar como se deja influir cada sujeto por las circunstancias, el medio natural y humano es parte esencial en su determinación. Toda situación, directa o indirectamente, es relativa a la colocación del sujeto en el mundo, el cual ofrece materia, ámbito y límites a su vigilia y a su acción posible. Las situaciones no son aisladas o desmontables por el análisis, como las piezas de un mecanismo. Pueden coexistir diversas situaciones, con sendas cualidades y fases diferentes, en forma como de constelaciones. En el tiempo se concatenan de la manera más compleja, al punto que una consideración estructural rigurosa justificaría el criterio de que la vida toda de cada hom- 
bre es el desenvolvimiento de una sola situación continua, cuya textura tendría sentido en la integración del todo formado por el sujeto con su mundo. Pero la intencionalidad distingue y aisla hasta cierto punto situaciones determinadas y precisas en el complejo de la realidad personal concreta. JASPERS đefine la situación como "una realidad conforme a ley natural y mayormente conforme a relación de sentido, que no es ni física ni psicológica, sino realidad concreta de ambos dominios, significando para mi vida ventaja o perjuicio, oportunidad o barrera... Porque la vida es un estar en situaciones, nunca puedo salir de una situación sin caer en otra". Por su parte, Nicol observa que "la acción se circunscribe en un aquí y un ahora, pero este aquí y este ahora son los del sujeto que actía. Ahora bien: si el actor inicia su acción, la inicia no sólo en un aquí y un ahora, sino en vista de ellos, por razón de algo concreto y determinable que en ellos se ofrece. Este algo concreto es la situación, a la cual llamamos vital porque estando en ella se organiza la vida del actor". "Ellhombręoestácen lat situación como las cosas están en el lưgag đule ocipani sino que el hombre vive la situación en que se encuentra, y el vivirla es uno de los componentes de la situación misma. El otro es lo que podríamos llamar lo transpersonal, la circunstancia".

Lo dicho bastaría para dar idea de la influencia de las situaciones sobre la organización temporal de la vida anímica. En las páginas que siguen volveremos a referirnos a ellas en relación con diversos aspectos del tiempo vivido. Pero no podemos pasar adelante sin indicar siquiera lo más pertinente y esencial, aunque difícil de expresar en términos directos. Las situaciones constituyen to que puede llamarse la trama dramática de la temporalidad humana. Toda 
situación vivida encauza de algún modo la continuidad anímica, insertándola en la sucesión de los hechos del mundo y despertando resonancias y movimientos especiales en la intimidad personal. El conjunto vicisitudinario de las situaciones fluye en un horizonte muđadizo, representado tanto por el escenario objetivo cuanto por el fondo del mundo subjetivo. Además, hay situaciones por sí mismas continuas, a las que se atiene la vida interior en renovado y obscuro apremio de sustentación en el tiempo y por encima del tiempo. JASPERs las llamà situaciones límite. Son aquellas que no pueden ser abarcadas ni superadas; se transforman sólo en lo que respecta al modo de manifestarse, pues están ligadas definitivamente a nuestra vida, como el miro lo está ại esnacis de nuestra habitación; frente a ellas no podemos reaccionar sensatamente con premeditación para modificarlas sino entregándonos a su entidad de una manera especial, iluminándola en nosotros mismos, en la marcha hacia las posibilidades intrínsecas de nuestra existencia: "devenimos nosotros mismos al avanzarecon losojos abiertos en las situaciones límite...Jexperimentar las situaciones límite y existir es la misma cosa". Situaciones límite son el hecho de estar siempre en situaciones, el de no poder vivir sin luchar y sin sufrir, el hecho de tomar inevitablemente la propia culpa sobre sí mismo y, por último, tener que morir.

4. Respecto a los "acoplamientos constantes" incluídos en la conexión adquirida de la vida anímica, Dilthey señala como modalidades principales: imágenes, conceptos, determinaciones de valor, ideales, direcciones de la voluntad consolidadas. Aquí consideraremos en general lo vivido, to hecho (en el más amplio sentido), en tanto que impone de alguna manera su carácter a lo actual y por vivir, configu- 
rando correspondientemente los procesos psíquicos sucesivos. No es sólo el efecto de la memoria y el hábito, sino la propensión general a durar, como un eco, ínsita en lo constituído una vez. Acoplamiento quiere decir aquí una estructura relativamente cerrada capaz de imponer algo de su forma o de su contenido a los estados y actos nuevos, impregnándolos, por decirlo así, con la esencia del pasado. Esto es lo que entendía Herder al afirmar que las impresiones de la mocedad "forman la urdimbre en la cual, más tarde, el destino y la madurez de entendimiento nos dan el tejido". Es la misma realidad psicológica a que se refieren con extrema insistencia los psicoanalistas, la "fijación", con la que vinculan la génesis de los acoplamientos llamados por ellos "complejos". A este propósito conviene recordar que uno de los motivos de la división existente entre las principales sectas de psicoanalistas es el del alcance atribuído a la influencia del pasado. De un lado, Freud y sus seguidores más adictos tienen un criterio excitisivamente determinista, según el cual los complejos adquiridos enela infancias rigen todas las reacciones del adulto, cuya actividad subconsciente tiende sin cesar a la regresión; de otro lado, Jung, Silberer, Maeder y otros admiten que la vida anímica se configura, en cada situación, tanto por las influencias đel pasado, cuanto por la dirección de las tendencias prospectivas.

Lo efectivo, más allá de toda concepción de escuela, es que la vida anímica constituye una estructura dinámica total en cuyo decurso se adquieren propensiones parciales más o menos consistentes, susceptibles de reforzarse, transformarse o desaparecer, según sean las disposiciones innatas que prosperen en el desenvolvimiento de cada sujeto y según 
el influjo de adquisiciones posteriores, sin mengua de la espontaneidad original inherente a todo verdadero devenir concreto. Insistimos en este último punto con el deliberado intento de dejar en claro la limitación pertinente, contenida ya en lo dicho, al afirmar que lo vivido impone "de alguna manera" su carácter a lo actual y por venir. En realidad, en el curso irreversible del tiempo, jamás se opera un retorno absoluto de lo pasado, nunca el mundo del yo es idéntico en dos momentos, y nunca una impresión o propensión deja de formar parte de la totalidad estructural.

$55^{\circ}$ El último aspecto de la organización temporal del conjunto de la vida anímica es el constituído por los procesos creadores. En ellos resalta la eficacia del instante en los actos determinativos de valores y conexiones estructurales que surgen por primera vez, aunque no sin el concurso de condiciones y estados anteriores. Dilthey señala, junto a síntesis originales del entendimiento, formas simbólicas artísticas, que agitan la vitalidad íntima, y direcciones apasionadas de la voluntad. Nosotros trataremos de precisar nuestro concepto respecto a los momentos que en general por su agudeza y por 1 a novedad el inportancia de lo vivido transforman más o menos hondamente el curso de la existencia. La mayor parte del tiempo nos ocupa lo trivial, cuyo dominio está en proporción inversa del caudal de nuestra espontaneidad y de los cambios exteriores. En un ambiente lleno de estímulos para el individuo de natural sensible y espíritu fecundo, los procesos creadores dan a la vida anímica el carácter de metamorfosis continua. Esto es particularmente ostensible en ciertas épocas críticas de la mocedad, durante las cuales las disposiciones se truecan en actualidad promisoria en el seno de un mundo que es nuevo para el sujeto. En el hombre adulto, aunque las experiencias inesperadas obran 
transformando y matizando la síntesis original de la existencia, las mutaciones decisivas son raras y por lo general dependientes de situaciones muy especiales. Siempre que se produce una conversión de cierta entidad, sea por la iluminación de nuevas ideas o certidumbres, sea por emocionés profundas y significativas o por decisiones trascendentales de la voluntad, nace una estructura que abarca toda la actividad interior y le imprime un impulso colmado de consecuencias. No obra como un hecho cualquiera, sino como una verdadera revelación del instante, de ese instante determinado y único, cuyo sentido renueva la configuración de la experiencia adquirida, reforma los designios y cambia la actitud fundamental de la persona, especialmente en el aspecto más directamente ligado con el contenido - a la vez concreto y representativo- de la situación provocadora. Al referirnos a ideas, emociones y actos de la voluntad no queremos significar que la conversión operada consista, respectivamente, en un vuelco intelectual, afectivo o volitivo, según los casos, sino que puede haber un áspecto psicológico más saltante en el conjunto de la manifestación, siempre complejo. En esta suerte de metamorfosis interviene indefectiblemente, en grado variable, la actividad intelectual, a menudo en forma de una "cristalización" súbita del criterio frente a las condiciones dadas, cuya importancia específica aprehende. También el sentimiento interviene en todos los casos; sin él es inconcebible la agitación de la vitalidad íntima y la revolución valorativa con que se cumplen el contraste y la sintesis de las fuerzas hasta entonces vivas y las que despiertan en el instante. Por último, las disposiciones para la acción necesariamente entran en vigor en toda mudanza anímica cuya esencia es el nacimiento de tendencias determinantes de una configuración original de la actitud. 
Semejante conmoción de todo el ser subjetivo, "salto cualitativo" (KIERKEGAARD), puede asimilarse a un renacimiento. Principalmente en naturalezas frágiles, sea por la época dei desarrollo (fase crítica), sea por la constitución psicofísica (personalidad neuropática o psicopática), o por ambas circunstancias, las situaciones agudas de contenido penoso provocan, más que un renacimiento, la paralización y hasta la aniquilación de ciertos aspectos de la espontaneidad sana. El nombre que conviene a semejante emergencia, inhibitoria de la capacidad de reacción valiosa y formativa, es el ya consagrado de "traumatismo psíquico".

A propósito de la adaptación de las impresiones a las condiciones vitales, Dilthey emplea especialmente el concepto de articulación "para expresar que la conexión viviente es el fundamento de todo desarrollo, y que todas las diferenciaciones y claras y finas relaciones se desenvuelven de esta estructura, de la misma manera que el ser de un animal se desenvuelve del embrión". El concepto es pertinente aquí, donde examinamos el núcleo anímico de las situaciones importantes, pues éstas constituyen verdaderas coyunturas de la existencia, cuyollispecto dinámico tiene las propiedades de una estructura genética. $Y$ es estructura genética no sólo por el cambio que proyecta del presente al futuro, sino por la dependencia del presente y el futuro respecto del pasado, pues por mucho que tenga de improvisación creadora, el proceso no surge y no tiene los caracteres con que se manifiesta sino en virtud de la arquitectura previa del mundo subjetivo. En efecto, no basta que se reunan determinados accidentes de lugar y tiempo, por violentos que sean, para que el hombre reaccione con una transformación durable. Se requieren condiciones predisponentes y en cierto modo preparatorias, que dependen tanto de la constitución na- 
tiva cuanto de la experiencia anterior, organizada como un todo peculiar e histórico. No nos cansaremos de repetir que la situación vivida concreta es relativa tanto al estado de cosas actual cuanto a las propensiones personales del sujeto. Con plena razón observa Straus que "lo vivido subjetivamente por primera vez no necesita concordar con el hecho exterior. Una situación objetiva puede presentarse incluso a menudo [sin consecuencias] en el transcurso de una vida, hasta que, al fin, una vez provoca la visión de las significaciones generales representadas en ella. A menudo son matices completamente individuales los que hacen a un objeto apropiado para actuar como representante de una significación general. Sólo entonces la experiencia vivida es significativa; sólo entonces se produce la transformación. La experiencia adquiere el sello especial de novedad con el nexo de sentido que le da su consistencia concreta".

En suma, la conexión inmanente de la actividad anímica, la valoración personal, las situaciones, la experiencia adquirida y los acontecimientos renovadores tejen y coloran el paño de la vida individial en el misteriosoctelar del tiempo. El vigor y la peculiąridad dè licada una de semejantes condiciones, engranadas siempre en un conjunto singular, dan a la textura de la existencia su complicada imaginería, tras la cual la mirada del inquisidor afortunado descubre la hebra de oro entre la hilaza y, sobre el fondo desvaído de lo cotidiano, el dibujo de inextricables lacerías dejado por la vicisitud de los minutos y los años.

\section{El tiempo del yo, el tiempo métrico y el tiempo del mundo}

Como no se sabe qué es el tiempo en general, no hay un criterio único para referirse a él, sino múltiples puntos de vista, según el aspecto de la realidad que se considere. Por 
eso se habla de un tiempo de la física, de un tiempo fisiológico, * de un tiempo histórico, de un tiempo existencial etc. En psicología, el tiempo que se considera especialmente es el tiempo del yo. Ya Plotino intentó definirlo como la actividad del alma ejercitada en la creación y la generación, y en nuestros días HöNIGSWALD, llamándolo "tiempo inmanente", lo considera inseparable del despliegue de la vicła íntima de la personalidad. Pero la conciencia del tiempo no se limita a este aspecto, pues el hombre vive también ciertas modalidades del tiempo de la física, así como la temporalidad de los hechos exteriores, o tiempo del mundo.

En el tiempo de la física distinguimos dos aspectos principales: el cronométrico, en sentido estricto, y el teórico. Este último es visto bajo la especie del espacio, tanto comc tempus absolutum, sive duratio, según lo entendía NewTon, cuanto como dimensión físico-matemática, según la teoría de 1a relatividad, que en esto tiene antecedentes, descle hace más de un siglo, en las investigaciones de Lobatschewsky (I829). Tal aspecto del tiempo de la física no entra en la experiencia viva de da temporalidad. No sucede lo mismo con el tiempo cronométrico peselat hechorde que aquí el físico, según observa fundadamente BERgson, aunque puede acrecentar indefinidamente el número de los términos y restringir el de los intervalos, no logra jamás aprehender el contenido de éstos. $\mathrm{El}$ hecho innegable es que la mente humana está conectada con el tiempo cronométrico, probablemente por mediación del cuerpo. Para convencerse de tal vincula-

* R. S. LAOAPE dedica un estudio, A la recherche du temps vécu, París, 1935, al tema del tiempo fisiológice. La conelusión que puede sacarse de sı́ expresión que el autor aplica, sin fundamento no pasa de ser "puro concepto", en materia de tiempo físiológico nuestros conocimientos psicológico. Se ve qué ciablemente desde que K. VIERoRDT publicó su libros no han avanzado apre1868. 
ción basta recordar que reaccionamos adecuadamente a medidas de tiempo más o menos exactas, incluso sin la intervención de la conciencia vigilante. El caso típico es el despertar a una hora precisa cuando uno se propone seriamente conseguirlo, o cuando la sugestión lo determina en sujetos sometidos al hipnotismo, sin que intervengan el despertador ni ningún otro estímulo o referencia externa. Por eso se ha dicho que hay un reloj fisiológico o reloj cerebral en cada organismo humano. *

Con respecto al tiempo del mundo, nos parece legítimo distinguir, en principio, el proceso del devenir - que se cumple en los seres y en el cosmos-, de la temporalidad pública, condicionada por influencias exteriores. Cada indiviđuo, además de la duración propia que vive en todo instante de una manera privada y más o menos implícita, tiene conciencia de codevenir con el proceso de la naturaleza y de los demás seres particulares; el ritmo de sus días y sus años no le es exclusivo: participa de ellos con las demás entidades de su mundo, sobre todō con los đemás hombres. El tiempo, como el espacio, es vínculo de comunidad de vida, tanto por la conciencia del codevenir cuanto por la modificación de la temporalidad vivida por influjo de la atmósfera cultural determinađa por los hechos sociológicos e históricos. En la realidad concreta no es fácil marcar el límite que separa estas dos clases de influencias. El sentimiento del tiempo, como lo ha mostrado admirablemente Spengler, varía con las

* Ya en $1896 \mathrm{~K}$. Groos abordó el problema del cálculo inconsciente del tiempo. Posteriormente, Ehrenwalid aplicó la expresión "reloj del organismo"' (empleada antes por GUYAU) para expliear la precisión de las determinaciones de la duración de los momentos, principalmente en estado hipnótico. Las investigaciones de E. R. JAENSCE indican que los individnos cuyo tiempo interior concuerda más con el cronométrico son los que pertenecen a los tipos de carácter integrado. Véase E. R. JusnsoH: Der Gegentypus, Leipzig, 1938, pp. 290-293. 
épocas y las culturas en forma muy significativa. Hasta qué punto depende tal variedad del proceso del devenir y descle cuál es prođucto del espíritu objetivado, es cuestión sobre la que se puede especular mucho, pero que no se sabe determinar positivamente. Seguramente nunca el hombre se ha preocupado tanto con el tiempo como en nuestra época, en que todo sujeto urbano no sólo tiene reloj al alcance de la vista y el oído, sino cerca de su corazón o sobre la arteria del pulso. No nos atrevemos a negar la importancia que tenga en esto el inmenso progreso de la técnica y el régimen económico de la existencia impuesto por las condiciones sociológicas; pero tampoco descartamos la idea de que semejante forma de vida sea expresión de uina fase evolutiva del proceso profundo del devenir humano.

Antes de pasar adelante deseamos recalcar que la conciencia del tiempo no sólo comprende el tiempo del yo, sino el tiempo métrico y el tiempo del mundo (métrico también a las veces). De suerte que se justifica tanto el concepto de cronognoscia cuanto los de cronometría y cronología, cuyas referencias respectivas se relacionan unas con otras en la compleja estructura de dả activiđad animica concreta. Para usar los términos introducidos por HönIGSWALD, diremos que el tiempo "inmanente" y el tiempo "transeúnte" forman parte del tiempo vivido: el inmanente, de manera primaria, el transeúnte u objetivo (métrico y del mundo), de manera secundaria. Normalmente se mantiene una relación harmoniosa entre el tiempo inmanente y el tiempo transeúnte; MINKOWSKI la denomina "sincronismo vivido" o del contacto vital con la realidad. 


\section{El presente, el pasado y el futuro}

El tiempo que vivimos en cađa uno de nuestros instantes no es sólo presente, pues el pasado no se nos ofrece de manera exclusiva en actos o estados retrospectivos, ni nos dirigimos al futuro únicamente en actitudes especiales de proyecto o programa. Por otra parte, es absurda la propensión inveterada de reducir el presente a una especie de punto temporal, porque lleva a considerar cada momento actual como carente de duración, como mero linde o nexo đe lo que fué y lo que será. El propio HeIDEgGER incurre hasta cierto punto en este extremo al afirmar que "la vida se manifiesta en la unidad de futuro y pasado como presente". El tiempo efectivo tiene tanto un ahora como un antes y un después, explícitos o implícitos en 'a conciencia. No es verdadero devenir si le falta uno de los tres aspectos de la temporalidad. LEIBNiz dijo una verdad definitiva con su sentencia: " $L e$ présent est gros de l'avenir et chargé du passé". A esta pluralidad dentro de la unidach cualitativa del instante, comparable con los colores encerrados en el rayo de luz, denomina Minkowski "despliegtie" del devenir. Precisamente gracias a la polaridad de pasado y futuro, insita en cada momento presente, es factible la clara distinción de los tres modos del tiempo. En efecto, no vivimos una superposición confusa de lo que es, lo que fué y lo que será, sino el ahora en continuidad con el antes y el después.

I. Aunque en psicología el presente puro es una abstracción, la actualidad del instante constituye fenómeno que cada persona vive con caracteres inequívocos. Ciertamente, se trata de una experiencia inefable, pero que diferenciamos con toda precisión de la del pasado y el futuro. El presente no sólo es el tiempo más positivo, consistente y pleno, sino 
el que nos permite afirmar de la manera más directa el ser y la existencia tanto de nosotros mismos cuanto del mundo, objeto de nuestra conciencia. Tal vez por eso el ahora se vincula necesariamente con el aquí. El presente constituye el centro vivo de las situaciones; éstas son efectivas y suscitan la reacción personal esencialmente por ser actuales. Otro carácter propio del presente es su capacidad de contener otros modos del tiempo o de referirse a ellos. Ya SAN Agustín distinguía el presente de los hechos actuales, del presente relacionado con los hechos pasados y del presente dirigido al porvenir: "lo presente de las cosas pasadas es el recuerdo actual de ellas; lo presente de las cosas presentes es la actual atención dirigida a las mismas, y lo presente de las futuras es la actual expectación de ellas" (praesens de praeteritis memoria, praesens de praesentibus contuitus, praesens de futuris expectatio). El presente es lo actual y a la vez el centro de organización de la temporalidad; constituye algo así como el escenario activo de la evocación del pasado y de la previsión del futuro. En él se reconstituye y cobra nueva vida lo que fué actualidad original, y en él se barrunta y hastarse prefija yllietermina lo que acontecerá en el futuro. "La más profunda tragectia de la existencia humana -observa BERDIAEFF - reside en que el acto realizado en el instante presente nos liga para el porvenir, para toda la vida, tal vez para la eternidad. ;Aterradora objetivación del acto consumado, que por si mismo no tiene a la vista esta objetivación! A eso corresponde el problema del juramento de fidelidad: votos monásticos, juramento conyugal, votos pronunciados en las órdenes caballerescas o en las sociedades secretas. Es el problema del destino proyectado al porvenir". Los límites y la complejidad del presente no se prestan a una determinación fácil. Según el contenido de la expe- 
riencia viva, el presente puede ser fugaz o constituir un lapso relativamente prolongado. Es más: pueden coexistir múltiples presentes, ya que el sujeto no vive una línea de hechos sucesivos e impenetrables, sino un horizonte complejo de referencias, más o menos relacionadas unas con otras. En el mismo instante que mantengo una actividad de largo aliento, puedo reaccionar a una contingencia, sin perjuicio de tener pendiente mi espíritu del desarrollo de uno o más acontecimientos que me interesan. JASPERS se refiere a una perspectiva mayor cuando expresa lo siguiente: "Figuradamente, puede concebirse el instante como capaz de ampliarse desde el círculo estrecho de la realidad presente sensible hasta los círculos infinitos del presente religioso o metafísico. En ambos extremos se experimentará muy vivamente el presente, pero cuanto más amplio se traza el círculo espiritual, tanto más fuertes son las exigencias del espíritu consigo mismo - aun cuando se trate del presente más amplio- para ser actualidad y tener actualidad. Así surge una tensión entre la necesidad sensible presente de la situación y el anhelo de hacer reablo más lejano'? Ocurre, pues, con el presente, mutatis mutandis, Plocqueecon das situaciones, que se constelan e involucran varias de entidad y de ȧmplitud diferentes. Sin embargo, desde el punto de vista psicológico, el presente no puede tener una amplitud tan grande como el presente gramatical.

Hay dos extremos en lo que respecta al grado de entrega del alma al instante actual. En uno están el momento indiferente, descoloriđo e insubstancial, que vivimos como mera temporalidad transitoria, y el momento pesado y lento, que sufrimos cuando nos dominan sentimientos de malestar, desaliento, tedio, angustia, desesperación etc., o cuando nos hallamos en situaciones de espera. En el otro extremo es- 
tán aquellos instantes en que el presente es vivido con relativa pureza, con intensidad o plenitud en determinadas condiciones de entusiasmo o atención, así como en estados de abandono y despreocupación, esto último especialmente en naturalezas propensas a la vida contemplativa. El presente es el tiempo principal de la mentalidad infantil. Frente a un mundo nuevo, lleno de cualidades e incentivos, el niño fácilmente se entrega, absorto, al acaecer del instante. Pero en toda edad, la vida anímica normal ofrece un estado en que el presente se da con relativa exclusión del pasado y del futuro, aunque sin verdadera plenitud: es el de los sueños. KLAGES describe el hecho en los términos siguientes: "Soñando vivimos... cada acontecimiento que fué una vez como si fuera ahora. No sólo las cosas se yuxtaponen a mectida que aparecen en sueños, sino también el espacio y el tiempo caen al plano de las simples imágenes especulares, y đe esa manera pierde su eficacia el elemento de toda separación: la extensión... Lo que fué está nuevamente ahí, y lo que va a suceder, ya se realiza. No nos encontramos en el torrente del tiempo, en que para cada ahora lo que fué se aleja retrocediendo, "sinos en ininterrumpido presente, con un ahora de movilidad ilimitada".

El presente đel abandono y el ensueño, aunque es presente casi puro, no es substancial. Presente substancial, tenso y significativo, es aquel que vivimos en los momentos de concentración y fecundidad del espíritu; en las situaciones kiecisivas, cuando son fuerza viva las incitaciones del pasado $\mathrm{y}$ destino futuro la intuición eficiente de determinadas posibilidades; en instantes en que nuestra existencia se eleva vigorosamente por encima de lo temporal y perecedero. Ya hemos indicado algo de esto a propósito de los aconteci- 
mientos renovadores. Después señalaremos lo atañedero a la relación de lo temporal con lo eterno.

2. El pasado no es sólo la suma de los momentos fenecidos, la sombra de los presentes que, consumados, retroceden en nuestra marcha hacia el porvenir. Tampoco es sólo lo que el olvido y el recuerdo alejan y aproximan, respectivamente, del foco de nuestra conciencia. El pasado es la substancia de nuestra duración. Comienza como "ahora" y pasa a constituír el fondo creciente de la experiencia vivida, elemento de nuestro ser personal histórico. Aunque no apasezca en la conciencia sino en mínima parte, como recuerdo, somos lo que somos y nos sentimos como nos sentimos en mérito de todo lo que fué vivido por nosotros, desde nuestro nacimiento hasta el instante áctual. Lo nuevo de cada uno de los estados y actos de nuestro yo es necesariamente r elativo a nuestro pasado y en parte condicionado por él. Sin duda ocurre que sentimos o nos representamos un hecho del pasado próximo o remuto en el momento presente como si fuese lo único retrospèctivocquedse actualizas y actúa ahora; pero en realidadoeb pasadoientero, comos una atmósfera o medio interior, contribuye a transfigurar el aspecto con. dicionado en nuestro devenir.

El pasado es adquisición definitiva, en cierto modo estática, pero también es virtualidad y dinamismo, algo que se anima y que nos anima. Es estático en el sentido que lo ya vivido posee una relativa inercia o rigidez: no deja de pertenecer a lo fenecido y no pierde las cualidades de la situación que le imprimió su sello. Mas a la vez, en grado variable, es contenido y disposición plástica, susceptible de adquirir nueva configuración y nuevo sentido en la estructura del momento actual. La transmutación de lo que fué en 
lo que es o será se opera en consonancia con la actitud íntima, a su vez condicionada por experiencias sucesivas y por la potencia original y renovadora de la vida. El contenido del pasado no sólo fué actualidad primigenia una vez, sino es matriz y matiz de la actualidad de cada momento de la existencia, y en ciertos casos incluso puede adquirir tardíamente una importancia para el destino del sujeto, mayor de la que tuvo cuando constituyó realidad prima de un momento presente.

Aunque el pasado jamás revive entera y exactamente, en circunstancias excepcionales cobra una actualidad tan viva, que puede decirse que se restaura y casi sustituye al presente. De una experiencia típica de este género, provocada por el olor de las flores de onagra, hace una descripción admirable el naturalista W. H. Hudson en su libro Idle days in Patagonia ( 1893 ). No resistimos a la tentación de reproducirla, aunque sea muy fragmentariamente. "Cuando aproximo una flor a mi cara y aspiro su perfume, experimento una conjuóción de placer penetrante y una transformación mental tan considerable que parece un milagro. Durante un espacio de tiempo tan corto que si se le pudiese medir se verificaría probablemente que no dura sino una fracción de segundo, yo no me encuentro ya en un jardín inglés tratando de evocar ese pasado desaparecido y de pensar deliberadamente en él; el tiempo y el espacio parecen anulados y el pasado se ha hecho presente. Estoy de nuevo sobre la pampa herbosa, donde acabo de dormir muy profundamente bajo las estrellas... Es el instante del despertar, y mis ojos se abren sobre la pura bóveda del cielo, enrojecida en su mitad oriental con un color tierno; $y$ en el momento en que la naturaleza se revela ásí a mi vista, en 
el frescor, en la belleza exquisita de la mañana percibo en el aire el perfume sutil de la onagra. Las flores me rodean por todas partes sobre kilómetros, sobre leguas en esta vasta planicie, como si el viento de la mañana las hubiese arrancado de este cielo oriental para diseminar por millones las pálidas estrellas amarillas en la superficie de las altas hierbas desecadas... Todo esto viene y pasa como un relámpago, pero la escena es precisa y la sensación correspondiente, la toma de posesión de una sensación perdida, es maravillosamente real". "La sensación súbitamente encontrada de nuevo es para nosotros más un momento que una simple sensación: es como la materialización de un pasado irremediablemente perdido". Posteriormente MArCel Proust ha descrito de manera no menos primorosa una serie de impresiones de esta clase en su famosa novela $A$ la recherche $d u$ temps perdu (I913-1927), * obra llena de profundas observaciones acerca del tiempo humano.

Sin duda con menos intensidad que Hunson y Proust, la mayoría de los hombres conocen momentos de esa índole. Un olor, un sabor, "In movimiento, un gesto, tuna melodía, una frase, excepcionalmente, un paisaje o un estado de ánimo, transportan de golpe nuestro espíritu a un momento pretérito, que revivimos con todo su sabor. A veces la sensación o el estado afectivo sólo nos da una vaga impresión de determinada atmósfera interior que nos parece característica de una época dada de nuestra existencia. En algunas personas ocurre esto especialmente en el instante que la conciencia pasa đe la vigilia al sueño. En la gradación que va desde este extremo hasta el del mero recuerdo, son comtines

* Recomendamos particularmente la lectura del comienzo del t. II de la última parte, Le temps retrouvé, París, 1927, pp. 7-38. 
a todas las personas estados en que el pasado afluye a la conciencia. Los sentimientos de nostalgia, añoranza, duelo, piedad retrospectiva, arrepentimiento, lealtad y amor a la tradición son las formas más sobresalientes del vínculo que liga el presente con el pasado. De una manera general, en el curso de nuestra vida, aunque en parte superamos incesantemente lo ya vivido, en parte también persiste la huella y el tenor de lo que fuimos. En la profundidad del sujeto adulto, aun del menos sentimental, alienta todavía mucho del alma del joven y el niño que fué. Esto es efectivo incluso en el caso de aquellos individuos, inconsecuentes e incomprensivos consigo mismos, que reniegan de su pasado o ridiculizan su ingenuidad o sus imperfecciones de antaño. Tolstoy ha expresado una verdad en esta sentencia: "Del niño de cinco años a mí no hay más que un paso; del recién nacido al niño de cinco años hay una distancia aterradora". Sin embargo, en esta primera época de la vida sitúan casi todos los hombres su paraíso perdido, que añoran más o menos obscuramente y cuyos hechos reales en ocasiones embellecen y abrillantan con simbolos y galas de la imaginación. Tanto en este caso como en el contrario - de aquellas personas que pasaron una infancia desdichada- la vida íntima del hombre adulto tiene en el mito de los albores de su personalidad algo así como un telón de fondo, no siempre desprovisto de influencia sobre la perspectiva actual de primer pla-
no.

Normalmente, pasada ia juventud, a medida que el hombre progresa en edad y a medida que disminuyen las expectativas de la existencia por acortarse el porvenir posible, aumenta la importancia e idealización del pasado en la experiencia viva de la temporalidad. Correlativamente, el pre- 
sente se vuelve menos rico, el correr del tiempo parece más veloz y los años y las épocas, que antes se juzgaban extensos o remotos, dan la impresión de abreviarse y dejarse abarcar más fácilmente que antes. Todo hace pensar que la conciencia del tiempo se torna más y más esquemática, por la mengua de lo imprevisto, el vigor de la rutina y la monotonía de la acción, pero sobre todo por la falta đe espontaneidad, falta anexa al cambio del tempo vital debido a la transformación del organismo, tanto menos ágil cuanto más antiguo.

$3 .^{\circ} \mathrm{El}$ futuro es la fuente de la temporalidad concreta. No puede ser considerado desde el punto đe vista psicológico sino como el más allá incierto hacia el cual se dirige la intencionalidad. Constituye lo contrario de lo realizado, y sin embargo compromete, acicatea y configura efectivamente la actividad anímica. Para el alma el porvenir es tan positivo como el presente, al cual no sólo continúa sino alimenta y forma, pues "tanto como lo pasado, lo venidero es condición del presente: lo que puede sercy lo que debeser son fundamento de aquello queres" (NIETzSCHE).vSislo antes vivido đa al alma el sostén de lo determinado, el camino hecho de tentativas, logros y fracasos, lo que queda por vivir, potencia intacta y promisoria, le ofrece el mundo de las posibilidađies. A él van el ensueño y la determinacióri, las aspiraciones y los propósitos, y de él dependen la perfección y la salvación o el descenso y la ruina de la propia existencia. Por su carácter potencial, el futuro se impone a ia conciencia del tiempo como umbral del devenir incierto y arcano. El futuro no es absolutamente potencial y virgen, abierto sólo a la renovación, pues el pasado y el presente lo condicionan, prefiguran e idealizan. Es excesiva, sin duda, la afirmación 
de Proust de que el pasado proyecta ante nosotros "la sombra de sí mismo que llamamos porvenir"; pero contiene parte de la verdad, que Nicol ha formulado con precisión. "No hay que entender por pasado sólo lo que fuimos - escribe-. Nuestro pasado se compone de lo que fuimos; de lo que podíamos ser y no fuimos; y de lo que sabemos que no pudimos ser. $Y$ en el presente, se articula con estos componentes del pasađo nuestra opinión sobre cada uno de ellos, y sobre la opinión que los demás forman de ellos y que se nos alcanza conocer. De ahí formamos la idea, proyectada hacia el futuro, de lo que no podemos ser, de lo que no sabemos si podremos llegar a ser'; de lo que queremos ser". En efecto, la relación del pasado con el porvenir plasma la vocación del hombre en el mundo, la orientación singular de su personaliđad, cuyas expresiones concretas se desenvuelven en la continuidad de la duración.

Se refieren a lo venidero una serie de actitudes entre las cuales precisa señalar las siguientes: la previsión y el abandono, la espera y la esperanza, el deseo y la preocupación, la libertad y el amor fati.

a) La "prevision dispone la existencia a lo que debe o puede sobrevenir. La estructura de la vida está dirigida por la aprehensión de infinidad de regularidades del acaecer. Lo que debe suceder necesariamente es tan firme y natural como los hechos actuales; con ello se cuenta de antemano. Lo que puede sobrevenir y lo imprevisible son del đominio del azar. En la vida anímica normal es amplio el margen que concede al azar la disposición para afrontar el porvenir, pues en el mundo no todo sucede de manera regular, conforme a los encadenamientos conocidos y al saber. Hasta cierto punto, el futuro es por excelencia futuro, es decir, tiempo 
virgen, gracias a este margen concedido a la contingencia. E1 abandono es la actitud adecuada para afrontarlo satisfactoriamente. En las personas inclinadas a tal abandono, la vida tiene el encanto $\mathrm{y}$ la intensidad anexos al disfrute de la novedad, la sorpresa, la aventura, el espectáculo admirable, en que los riesgos y peligros no carecen de atractivo. En cambio, en los individuos propensos en exceso a la previsión y al racionalismo, el devenir se empobrece y marchita en una perspectiva áriça y artificial.

b) Frente a lo que tiene probabilidad de suceder, el alma puede adelantarse con la espera o la esperanza. En la espera, se entrega de antemano pasivamente y con desmedro del momento actual. Con ella se produce una especie de retraccion del ser del hombre, ptes no permite vivir unidos o indepenclientes el presente y el porvenir inmediato, sino "el porvenir como tal, tiende a convertirse en presente" (Minkowski). La esperanza, al contrario, da vuelo a la experiencia de la temporailidad, enriqueciendo al yo gracias a la exaltación del valorotelo en idero, cuyologro a menudo es menos satisfactorio, desnudo yas del ropaje que le prestan el sentimiento y la fantasía precedentes a la realización. Tanto la fuerza promotora inherente a la expectativa cuanto el disfrúte đel bien con sólo vivir su posibilidad son, para quien espera, el premio anticipadio y la promesa de nuevas metas. Tal sería el fundamento psicológico de la sentencia de Heráclito: "Si no se espera, no se alcanza lo inesperado". El pesimismo y el optimismo guardan estrecha relación con las actitudes de espera y esperanza, respectivamente, sin que pueda decirse cuál es condición y cuál consecuencia, y sin que sea propio descartar la vinculación de estas con otras maneras de vivir el futuro. 
c) El deseo y la preocupación, en ctianto se orientan hacia el futuro, desvían la intencionalidad del presente al porvenir eventual, haciendo depender aquél de éste. Tal dependencia se une, en el deseo, a valores positivos para el sujeto, aunque atribuílos a bienes problemáticos. La preocupación se refiere a valores negativos, anexos a problemas, dificultades y peligros. Acompañada o no de temor o angustia, siempre ensombrece la experiencia de la temporalidad. Mientras que el deseo puede constituír acicate para superar las condiciones de la vida concreta, la preocupación frustra la existencia en la incertidumbre, enfrentando el devenir con una anticipación de la muerte sin arcanidad, como pura nada. HeIdegGer ha profundizado la inclagación fenomenológica y metafísica de esta actitud; desçraciadamente, su análisis del tiempo es dominado por todo lo que ve bajo la especie de esta dirección descendente de la temporalidad y la existencia. Sin salir del dominio de la psicología, podemos afirmar que la preocupación está limitada por otras disposiciones, que pueden superarla, dentro de la estructura total de la vida anímica.

d) "Jorge ? uccinelli converso.

d) La actitud más original y significativa frente al porvenir es la que se manifiesta en los actos absolutos de la persona, al asumir y superar con el espíritu las condiciones de su vida. En las decisiones y creaciones de la libertad y en el amor fati, adhesión al destino, el rlevenir trasciende de la mera temporalidad. Por encima de lo objetivo y de lo susceptible de objetivación, la libertad da principio a nuevas perspectivas y realizaciones de nuestra existencia. $Y$ dentro de las situaciones inevitables, gracias al anor fati logramos proseguir con plena responsabilidad propia la carrera de la vida en la vía condicionada, sufriendo sin desmedro los sa- 
crificios propios del cumplimiento de nuestra más alta y genuina vocación.

Aparte de las actitudes indicadas, el hombre vive especialmente el tiempo venidero, a menudo encareciendo su valor, por influjo de proyectos, ideales, utopías o anhelos proféticos. Incluso la ilusión de un porvenir muy lejano, inalcanzable durante la propia existencia, es capaz de orientar al alma hacia adelante. Si el presente es el tiempo principal de la niñez y el pasado el de la ancianidad, el futuro es el propio de la juventud. Esta tiene su mito del paraíso, no el del perdido con la infancia, sino el venidero, el que se conquista en el banquete de la vida. Pero la flor de la edad prenuncia efectivamente frutos de la madurez sólo en quien prueba ser capaz de lograrlos auténticos en la lucha heroica y desinteresada - sin sectarismo ni precipitación- en que vencen el amor y la alteza moral.

\section{Lo histórico y lo eterno}

La existencia es consmnacione del eser del hombre en el devenir, consumacióngenp elcdoblel sentidoedeopérdida, disipación, descenso a la nada, y de cumplimiento, logro, ascenso a la plenitud. En el primer sentido algo muere inevitablemente en nosotros a medida que el tiempo fluye; no sólo porque con el pasado se extinguen los fenómenos, sino porque en el presente se frustran disposiciones necesitadas de ocasión para prosperar, y nosotros mismos traicionamos infinitas virtualidades genuinas y esenciales de nuestra entidad espiritual - con lo cual sufrimos desmedro. Por eso tiene razón Nietzsche al advertir que debemos guardarnos de afirmar que la muerte es opuesta a la vida. Ciertamente, la muerte no sólo đe la manera mencionada entra en 
la vida; entra también como el término seguro de nuestra existencia terrenal - mors certa, hora incerta--, y de ese modo tanto puede dirigir la temporalidad hacia la nada como elevarla al plano de superior realidad espiritual. En efecto, la noción correspondiente da al devenir humano caracteres muy especiales por las resonancias que suscita en la intimiđad y por su repercusión sobre la estructura total del tiempo vivido: la conciencia de ser mortal. En tinos casos, a esta conciencia va unida una actitud evasiva, nihilista o de preocupación y derrota; en otros, la de entrega al misterio, resignada, valerosa o llena de consuelo y esperanza.

Cuando se consuma de manera positiva el ser en el devenir, la existencia cumple un sentido espiritual. Entonces logra realizaciones gracias a la aprehensión de esencias y valores, eternos aunque se manifiesten siempre en actos y obras temporales. El hombre es un ser histórico principalmente por virtud de esta capacidad de aprehender e incorporar lo eterno en el suceso. Un acontecimiento no sólo es cosa del presente $B$ del pasad6, adevenir objetivado, rotundo, sino hecho, realidadopara siemprelliLa conciencia histórica acoge la sucesión de los hechos concretos y singulares de la sociedad humana de que uno forma parte. En la conciencia histórica la jerarquía de los acontecimientos depende de la entidad efectiva de los mismos así como de su importancia para el destino personal. De ahí que para la mayoría de los hombres los sucesos ordinarios del círculo más próximo de la vida de relación ejerzan mayor imperio sobre su mundo interior que los grandes y excepcionales pero lejanos. En el primer plano de esta perspectiva, dependiente del sentimiento, el sujeto vive las resonancias íntimas de su experiencia y la relación de éstas con la totalidad sintética de su ser en 
devenir de suerte que el sentimiento de la historia privada es como el mordiente de la historia exterior. Así se comprende la relatividad de la conciencia histórica respecto de la experiencia subjetiva y, por consiguiente, el sentido y el alcance que tienen los hechos objetivos según el punto de vista de cada persona. Esto no significa que la historia sea en general un reflejo caprichoso de la mentalidad de cada uno. Aunque el conocimiento histórico arraiga en la continuidad $y$ las peculiaridades de la experiencia interior, la disciplina del espíritu es capaz de reducir las limitaciones y el poder deformante de lo subjetivo. En todo caso, la constitución de la experiencia interior no es un proceso ajeno a la asimilación de la externa - pues de la manera como se logra ésta depende la adecuación de aquélla. La cultura histórica, imposible de lograr sin un trabajo asiduo de información, de crítica y de desbastadura interior, tiene precisamente por objeto la precisión de tal ajuste. Naturalmente, el afinamiento del sentido histórico consiste sólo en el mayor avance o aproximación posibledèbespíritudhacia una meta ideal, pues la comprensión histórica es elartel larte difícib de aprehender selaciones y significaciones, por encima de los hechos, los personajes, las instituciones y las colectividades acerca de los cuales se documenta la ciencia histórica. Litr, que ha estudiado a fondo las cuestiones del cultivo de la historia $y$ la naturaleza de la comprensión histórica, formula esta idea: "Comprender puras legalidades es tarea racional; comprender individualidades vivientes es ocupación espontánea del yo, que puede llegar a ser vislumbre adivinatoria y configuiación artística".

El alma del sujeto capaz đe sentido histórico puede enLazar más o menos amplia y significativamente el pasado, el 
presente y el porvenir. Incluso el hombre con escasas nociones acerca de la historia, de hecho vive históricamente, atunque a menudo sea un tiempo de poca substancia a causa de que los momentos de su vidla se relacionan sólo con el aspecto más asequible de los momentos del mundo. "El hombre comienza a vivir históricamente tan pronto como entra en relación recíproca con su medio, y comienza de modo primitivo a conocer lo histórico tan pronto como trata de comprender su esencia humana” (LıтT). En épocas de vida pública tranquila y en un ambiente poco abierto a las influencias de fuera, la conciencia histórica enfrenta casi exclusivamente ios sucesos domésticos y locales. En cambio, en épocas y ambientes de grandes acontecimientos públicos, los más de los hombres siguen con interés el curso vivo de la historia. En uno y otro extremo la experiencia exterior es vivila y conocida de acuerdo con los antecedentes y la estructura de las situaciones personales. La disposición individual, la educación, la tradición racial y cultural, el complejo enlace sociológico de la ğenteración actual y todaesuerte de influencias externas formane inclinatil la actitudodel sujeto en lo que respecta a acoger los acontecimientos y dejarse estimular por ellos. El común de las gentes - por ingenuidad o flaquezavive pasivamente el espíritu de la época y es fácilmente víctima de falsas interpretaciories y de sugestiones tendenciosas de parte interesada en deformar el criterio público. Esta manera de someterse a las opiniones reinantes, ruinosa para la personalidad, encuentra poca resistencia íntima cuando el interés vulgar y la sed de excitaciones y halagos dominan en las almas desprevenidas o laxas. Entonces, con el deseo exacerbado, engañoso y desorientador, la multitud vive el tiempo aprisa y superficialmente, en la mudanza de instan- 
tes vacuos, sin coherencia ni tensión. Pero si el desarrollo de los sucesos adquiere suma importancia, la colectividad adopta con exaltación el ritmo y la intensidad del crama histórico. En tal situación se encienden las pasiones y fácilmente se estrecha y anubla la conciencia histórica. Con esto, la legión dé los débiles de espíritu y la no menor de los flacos de voluntad se hacen sectarias, incapaces de discernir y juzgar, dispuestas, por el temor o por el odio, a abrazar todas las posibiliclades estimulantes y a llevar a la acción sus más extremas consecuencias.

Si la conciencia histórica anublada y estrecha esclaviza el alma a la cosa finita, la iluminada y plena la eleva a la visión de lo eterno. Con objeto de evitar todo equívoco, antes de pasar adelante declaramos referírnos aquí a la experiencia vivida de lo eterno, hecho anímico que conoce incluso el hombre positivista en teoría. No especulamos, pues, acerca de la eternidad ni tratamos de propugnar ninguna concepción religiosa o metafísica. Lo que se consuma en el tiempo, pese a la eventual desaparieión de las cosas en que se objetiva, en tanto que astmeo delai conciencialehistórica, incorpora en la existencia entidad definitiva. Lo que nos entusiasma y admira en Sócrates, por ejemplo, es el significado imperecedero de sus palabras y actitudes; y la revelación de este significado en un momento dado de nuestra vida, no pertenece sólo a la temporalidad de nuestra experiencia, sino que es asumida en una plano superior del espiritu, por encima del tiempo. Ciertamente, es tarea muy difícil intentar siquiera un análisis fenomenológico de la conciencia dirigida a lo eterno. Como la dirigida al tiempo, es inseparable del contenido distinto de la experiencia, y se la alcanza indirectamente, in modo obliquo, en infinidad de manifestacio- 
nes que la contienen de manera mayormente implicita. Una primera y segura aproximación fenomenológica nos la ofrecen las siguientes reflexiones de JAspers: "Si estoy arraigado en lo histórico, el ser temporal no tiene importancia en sí o por sí mismo, sino en el sentido que se decide en el tiempo para la eterniclad. Entonces el tiempo es posibilidad como futuro, sujeción leal como pasado, decisión como presente. Pues en tal caso no es sólo transcurrir, sino manifestación de la existencia, que se conquista por sus decisiones en el tiempo. Entonces lo temporal que tiene esa importancia con la respectiva conciencia, a la vez es superado y no en provecho de una intemporalidad abstracta, sino de modo que permanezco en el tiempo y por encima d'el tiempo, no fuera del tiempo. En tanto que soy conciencia de una vida, dominado por tendencias instintivas vitales y sus deseos finitos de felicidad, quiero duración en todo tiempo, como si fuera rescate de la angustia de vivir en la mera duración. Como conciencia viviente no puedo anular estos deseos, de la misma manera que no puedo abolir el pesar de lo perecedero. Pertenecen a mi vida como tal. Pero, en tanto que actúo de manera incondicional, que amo de manera incondicional, la eternidad está en el tiempo. Esto no lo conceptúa mi entendimiento: resplandece en el instante y después sólo en el recuerdo dubitativo. No tengo nunca la eternidad como pose-
sión manifiesta".

$\mathrm{E} 1$ instante se vive como tiempo fugaz o como momento vinculado con la eternidad. La diferencia depende tanto de la indole de lo experimentado cuanto de la calidad intrínseca del sujeto, de la substancia de su ser espiritual. Sólo puede alcanzar la impresión de lo eterno quien vive el presente con profundidad y de cierta manera. El místico, el 
poeta, el héroe, el sabio conocen especialmente esa profundiclad y esa manera. Para ellos es válida la sentencia de Goethe: "Todo estado, mejor dicho, todo momento tiene un valor infinito, pues es representante de toda una eterniciad". Pero el instante se explaya hacia la eterniđad en cua!quier hombre capaz de maravilla, de entusiasmo, de intuición del destino o de sentimiento de responsabilidad inalienable. Podemos vivir en el tiempo y allende el tiempo especialmente cuando llega hasta el penetral de nuestro espíritu el destello de un valor auténtico encarnado en la realidad exterior o en nuestra existencia, cuando aprehendemos una conexión de finalidad esencial entre los seres y el cosmos o se revela a la contemplación solitaria el misterio que nos rodea, cuando se hace patente al yo la originalidad de un acto libre y creador, en fin, cuando estamos penetrados de la certiclumbre de morir o de cierta clase de separaciones definitivas. En estos y otros casos el momento es en cierto modo "átomo de la eternidad" (KIERKEGAARD). Y cabe afirmar que el hombrei conoce cel tiempo propiamente humano sólo cuando se le transparentailopinperecedero en el fluir de lo transitorio. *

Lo eterno no sólo asoma en momentos privilegiados. Toda nuestra existencia, en la medida que tiene profundidad, es una lucha, un esfuerzo, un anhelo de sustentación en algo más que lo trocable y finito del ahora - tanto en quien cree

* Según esto, la duréc véelle bergsoniana, tiempo vivido de manera subespiritual, no es el tiempo humano por excelencia. El barón vox Hǘget considera que el concepto de duración tal como lo entiende Bergsos corresponde al de aevum de Santo Tomís DE AqusNo: el aevum, distinto del tiempo y de la eternidad; no tiene ni antes ni después, aunque ambos pueden relacionarse con a. Las criaturas espirituales, que participan de la eternidad, son medidas por el acvum sólo en lo que atañe a su ser natural. (Véase WILliam RaLPH Isge: The philosophy of Plotinus, London, 1923, t. II, pp. 100-101). 
como en quien no cree en la inmortalidad del alma. La vida en su totalidad y en su posibilidad inexhausta, la identidad personal, la vocación frente al mundo y al idẹal y la síntesis de todo esto, el sentimiento del hombre no las atribuye espontánea e íntimamente al puro devenir, sino al ser oriundo de la eternidad. Aunque no lo formule como lo hizo PLATón, para la mentalidad mítica de todo hombre el tiempo es "una imagen" móvil de la eternidad".

Maurice Blondel ha expresado con acierto la idea del nexo vivo de lo temporal con lo eterno en el alma humana. En su obra $I$ a pensée formula esta verdad elemental: "No tenemos el sentimiento de la duración, del cambio, de la relatividad sino por tina referencia permanente a la idea real en nosotros de la eternidad; de lo absoluto, del modelo fijo que, en el devenir mismo, está por encima del devenir, y que forzosamente permanece la explicación de nuestro pensamiento y el término indeclinable de nuestro deseo". En L'action desarrolla el mismo sriterio en forma que debe recoger todo psicólogo: "Si la jdea no es nađa sin el sentimiento, lo real tampoco tiene influencia alguna sobre nosotros sin el ideal; y no actuamos sino en vista de lo que todavía no es: el principio de la acción consciente, para ser eficiente, supone una causa final que le es a la vez interior y trascendente. Pues no sólo el hombre no vive humanamente sino para lo que todavía no es, para el porvenir...; sino que, más imperiosamente aún, coloca, bajo este prolongamiento en la duración, bajo este ensanche de sus conquistas esperadas, una aspiración de otro orden y que, acaso sin sospecharlo, transporta su ímpetu hacia un plano superior al tiempo y al espacio. Es menester agregar todavía que no tendríamos la menor conciencia de porvenir y de progresión si no tuviése- 
mos implícitamente una necesidad de liberación e infinitud. No actuamos, pues, en este mundo y sobre este mundo sino rebasándolo para transformarlo, descontando, por decirlo así, otro mundo, reglando nuestros actos sobre concepciones ideales y empleando una voluntad ya emancipada del determinismo de la naturaleza”.

Frente al fluir de los acontecimientos la conciencia histórica del individuo se ocupa continuamente en un trabajo de depuración. En él perece o es descartado lo transitorio e insubstancial, y se concentra y conserva lo que significa realización singular de valores en acción humana, resiđuo de eternidad. Las noticias acerca de la aparición y el tránsito de los personajes en la escena del mundo, lo mismo que la vida y las obras de las figuras familiares del ambiente inmediato, suscitan ese proceso, comparable a la separación del diamante de la masa de carbón. E1 precioso residuo es manifiesto en lo que nosotros llamamos el panteón interior: la representación de los muertos queridos persiste en nuestro recuerdo despojadal gradualmente de los accidentes de

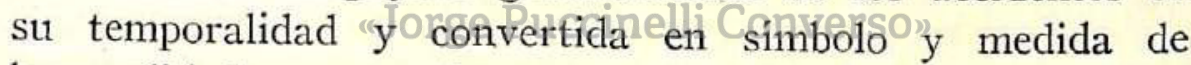
las cualidades que mejor encarnaron. De la misma manera, la historia asimilada por la existencia personal se convierte en fondo del pasado propio y en substancia intemporal de nuestro espíritu. Gracias a ese proceso, lo eterṇo, encarnado una vez en receptáculo perecedero, de nuevo transfigura la viđa. Así, sub specie aeternitatis, adquiere un segundo sentido, superior, la frase de WiLhelm von Humboldt: "Todo lo que es eficaz en la historia también se mueve en el interior del hombre".

Pero la historia no sólo ilumina y orienta la existencia cie los hombres reflexivos y piadosos por lo que tiene de su- 
blime y venerable: también la profundiza y le da temple por lo que entraña de tenebroso y terrible. Tal es la causa de la imperativa amonestación de Berdiaefr, nunca más oportuna que en el peligroso momento que vivimos: "Este conflicto trágico, esta antinomia insoluble en nuestro mundo, es menester que los asumamos y los atravesemos. Es menester asumir la historia, asumir la cultura, asumir este espantoso y doloroso mundo decaído. Pero la ú1tima palabra no la tiene la objetivación: esta última palabra se deja oír en nosotros procedente đe otra región del ser. $Y$ el mundo de los objetos expira, expira en el umbral de la eternidad, enriqueciclo por la experiencia trágica”.

\section{BIBLIOGRA EIA}

San Agustín: Confessiones, Nova editio, curante P. A. C. Vega, O. S. A., El Escorial, 1930.-Nicolas BerdiaefF: Cinq méditations sur l'existence, Paris, 1936.-Henri Bergson : Essai sur les données immédiates de la conscience.Paris, 1912-Brason : Durée et' simultanéité, Paris, 1929. MAURICE Blonderto La pensée, t. II, Paris, 1934.-Blondel : L'action, t. U, Paris, 1937.-ERnst Cassirer: "Phänomenologie der Erkenntnis", P.hilosophie der symbolischen Frormen, t. III, Berlin, 1929.-Wilhelm Diшthex: "Ideen über eine beschreibende und zergliedernde Psychologie", Gesammelte Schriften, t. V, Leipzig u. Berlin, 1924.-DintHex: "Entwürfe zur Kritik der historischen Vernunft", Gesammelte Schriften, t. VII, Leipzig u. Berlin, 1927.-Fritz Giese, Hans W. Gruhle u. F. Dorsch: Theodor Elsenhans Lehrbuch der Psychologie, Tübingen, 1939.-Guyau: Génesis de la idea de tiempo (Trad. del francés de Ricardo Rubio), Madrid, 1901. - Martin Heidegger: Sein und Zeit, Halle a. d. S., 1931.-EdnUND HusserL: Vorlesungen zur Phänomenologie des inneren Zeitbewusstseins, Herausgegeben von Martin Heidegger, Halle a. d. S., 1928.-Willinm James: Principles of Psychology, t. I, New York, 
1918.-Karl Jaspers: Psychologie der Weltanschauungen, Berlin, 1925.-Jaspers: Philosophic, 3 ts., Berlin, 1932.-Ludwig Klages: Der Gist als Widersacher der Seele, ts. I \& III, Leipzig, 1929 \& 1932.-Paul L. Isandsterg: Einführung in die philosophische Anthropologie, Frankfurt am Main, 1934.-THEodon LiтT: Geschichte und Leben. Probleme und Ziele kulturwissenschaftlicher Bildung, Leipzig u. Berlin, 1930.- E. Mrnkowskr: Le temps vécu. Études phénoménologiques et psychopathologiques, Paris, 1933.-Eddardo Nicol: Psicología de las situaciones vitales, México, 1941-—EdousRD Picron: "Essai d'étude convergente des problèmes du temps", Journal de Psychologie Normale et Pathologique, 1931, No. 1-2.-K. SAPPER: "Zeitbewusstsein und Zeitschema", Screntia, 1938, Nos. 1012.-Erwin Straus: Geschehnis und Erlebnis, Berlin, 1930.Straus: Vom Sinn der Sinne, Berlin, 1935.-J. von UexküLu: Theoretische Biologie, Berlin, 1920.

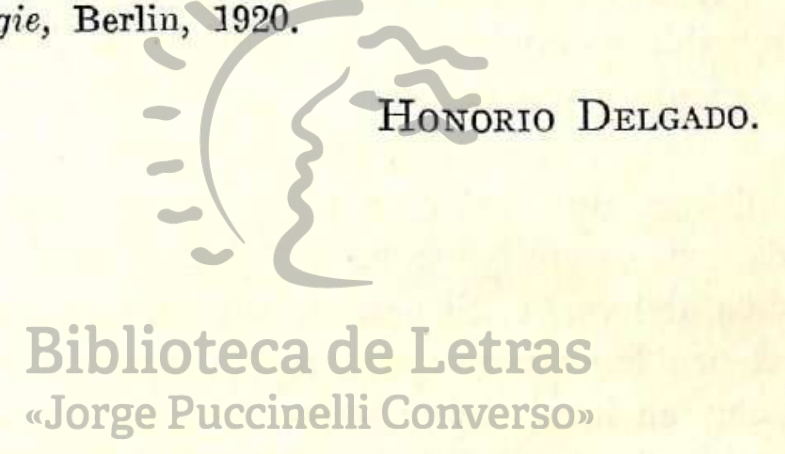

